\title{
The Interaction of Human Glutathione Transferase GSTA1-1 with Reactive Dyes
}

\author{
Mohammed Hamed Alqarni ${ }^{1, *}$, Ahmed Ibrahim Foudah ${ }^{1}{ }^{(D}$, Magdy Mohamed Muharram $^{2,3}$ and \\ Nikolaos E. Labrou $4, *$ (D) \\ 1 Department of Pharmacognosy, College of Pharmacy, Prince Sattam Bin Abdulaziz University, \\ Alkharj 11942, Saudi Arabia; a.foudah@psau.edu.sa \\ 2 Department of Pharmaceutics, College of Pharmacy, Prince Sattam Bin Abdulaziz University, \\ Alkharj 11942, Saudi Arabia; m.moharm@psau.edu.sa \\ 3 Department of Microbiology, College of Science, Al-Azhar University, Nasr City, Cairo 11884, Egypt \\ 4 Laboratory of Enzyme Technology, Department of Biotechnology, School of Food, Biotechnology and \\ Development, Agricultural University of Athens, 75 Iera Odos Street, GR-11855 Athens, Greece \\ * Correspondence: m.alqarni@psau.edu.sa (M.H.A.); lambrou@aua.gr (N.E.L.)
}

check for updates

Citation: Alqarni, M.H.; Foudah, A.I.; Muharram, M.M.; Labrou, N.E. The Interaction of Human Glutathione Transferase GSTA1-1 with Reactive Dyes. Molecules 2021, 26, 2399. https://doi.org/10.3390/ molecules 26082399

Academic Editor: Marko Goliĉnik

Received: 28 February 2021

Accepted: 16 April 2021

Published: 20 April 2021

Publisher's Note: MDPI stays neutral with regard to jurisdictional claims in published maps and institutional affiliations.

Copyright: (c) 2021 by the authors. Licensee MDPI, Basel, Switzerland. This article is an open access article distributed under the terms and conditions of the Creative Commons Attribution (CC BY) license (https:// creativecommons.org/licenses/by/ $4.0 /)$.

\begin{abstract}
Human glutathione transferase A1-1 (hGSTA1-1) contributes to developing resistance to anticancer drugs and, therefore, is promising in terms of drug-design targets for coping with this phenomenon. In the present study, the interaction of anthraquinone and diazo dichlorotriazine dyes (DCTD) with hGSTA1-1 was investigated. The anthraquinone dye Procion blue MX-R (PBMX-R) appeared to interact with higher affinity and was selected for further study. The enzyme was specifically and irreversibly inactivated by PBMX-R, following a biphasic pseudo-first-order saturation kinetics, with approximately $1 \mathrm{~mol}$ of inhibitor per mol of the dimeric enzyme being incorporated. Molecular modeling and protein chemistry data suggested that the modified residue is the Cys112, which is located at the entrance of the solvent channel at the subunits interface. The results suggest that negative cooperativity exists upon PBMX-R binding, indicating a structural communication between the two subunits. Kinetic inhibition analysis showed that the dye is a competitive inhibitor towards glutathione (GSH) and mixed-type inhibitor towards 1-chloro-2,4-dinitrobenzene (CDNB). The present study results suggest that PBMX-R is a useful probe suitable for assessing by kinetic means the drugability of the enzyme in future drug-design efforts.
\end{abstract}

Keywords: anthraquinone; chemotherapy; enzyme inhibitor; glutathione transferase

\section{Introduction}

Glutathione transferases (GSTs) are phase II detoxifying enzymes that catalyze various detoxification reactions [1-5]. GSTs exist and function as homo- or heterodimer proteins. Each subunit has an active site consisting of a polar GSH-binding site (G-site) and an adjacent hydrophobic binding site for electrophilic substrates (H-site) [2,4,5].

The five isoenzymes (GSTA1-A5) of the alpha class are encoded by a gene cluster that contains five genes localized on chromosome 6p12. Human tissues widely express GSTA1, A2, and A4 transcripts, whereas expression of GSTA3 is rare, and GSTA5 has yet to be detected in human tissues $[3,6,7]$. The isoenzyme hGSTA1-1 is primarily expressed in the human liver, representing $2 \%$ of the total cytoplasmic proteins [3]. It is also found in the kidney and various other human tissues [3]. It has been extensively studied since it catalyzes the detoxification of a wide range of electrophilic compounds, including carcinogenic metabolites, environmental pollutants, polycyclic aromatic hydrocarbons and diol-epoxides. Among the electrophilic compounds that are detoxified by hGSTA1-1 are several alkylating chemotherapeutics that are used in the treatment of cancer (e.g., busulfan, chlorambucil, etc.) [8-14]. This phenomenon, in combination with the overexpression of GSTs in cancer cells, is associated with developing resistance to many 
anticancer drugs $[14,15]$. In addition, GSTs have been shown to contribute to resistance to chemotherapeutic agents by regulating cell signaling pathways that control cell proliferation, apoptosis and redox homeostasis [7,16-18]. Furthermore, hGSTA1-1 suppresses JNK signaling activation by proinflammatory cytokine and oxidative stress, suggesting a potential protective role of hGSTA1-1 against JNK [19]. These actions of hGSTA1-1 are of great significance since they may compromise the efficacy and, therefore, the successful outcome of therapeutic approaches. To this end, one of the strategies being developed to address this problem relies on applying GST-targeted inhibitors. Numerous compounds with different degrees of efficacy and inhibition potency have already been studied over the last years [7,11-15,20-24]. GST inhibitors are classified according to their binding specificity $[1,5]$. Those that bind to the G-site or H-site and those that bind to the ligandinbinding site (L-site). The existence of a distinct L-site has been confirmed in several GST isoenzymes, including hGSTA1-1 [25-29]. The L-site role remains obscure, although it has been suggested that is involved in the storage and rapid transport of lipophilic molecules in the aqueous phase of the cell.

In the present work, we investigate the interaction of a range of dichlorotriazine dyes with hGSTA1-1, aiming at assessing their ability to function as irreversible probes/inhibitors towards the enzyme. The results of the present work provide new insights into the specificity of the ligandin-binding site. The study's outcome can facilitate a more rational approach for developing effective GST-targeted chemosensitizers for reversing anticancer drug resistance.

\section{Results and Discussion}

\subsection{Screening of the Inhibition Potency of DCTD}

Reactive dyes are useful and versatile tools for probing structure-function relationships in various proteins, including GSTs [30-33]. Four widely used dyes that belong to the anthraquinone and diazo group (Figure 1) were screened for their ability to bind and inhibit the isoenzyme hGSTA1-1. The results showed (Figure 2) that the anthraquinone dye PBMX-R displayed a higher inhibition potency, and therefore, it was selected for further study. The ability of the anthraquinone dye Cibacron blue 3GA (CB3GA) to inhibit the activity of other GSTs has been previously investigated [31,34,35]. For example, CB3GA has been used as a diagnostic probe to classify the mouse GST isoenzymes [35]. In addition, the interaction of CB3GA with the isoenzyme hGSTP1-1, which is involved in developing resistance to several anticancer drugs, has been investigated by X-ray crystallography [34]. More recently, the interaction of CB3GA and its structural fragments with the isoenzyme SjGST from Schistosoma japonicum was investigated [31].

The dye PBMX-R (Figure 1) possesses an electrophilic reactive dichlorotriazine moiety which is susceptible to chemical modification by several nucleophilic side chains in proteins. Therefore, it can react covalently with proteins and enzymes [30-32].

\subsection{Inactivation of $h G S T A 1-1$ by PBMX-R}

When hGSTA1-1 was incubated with PBMX-R, the enzyme activity was progressively diminished in a time (Figure 3) and concentration-dependent manner (Figure 4). Under identical conditions, the omission of PBMX-R from the incubation mixture results in loss of enzyme inactivation. Chromatography of the reaction mixture by gel filtration on Sephadex G-25 column did not recover the enzyme activity, indicating the formation of a covalent complex between hGSTA1-1/PBMX-R. 


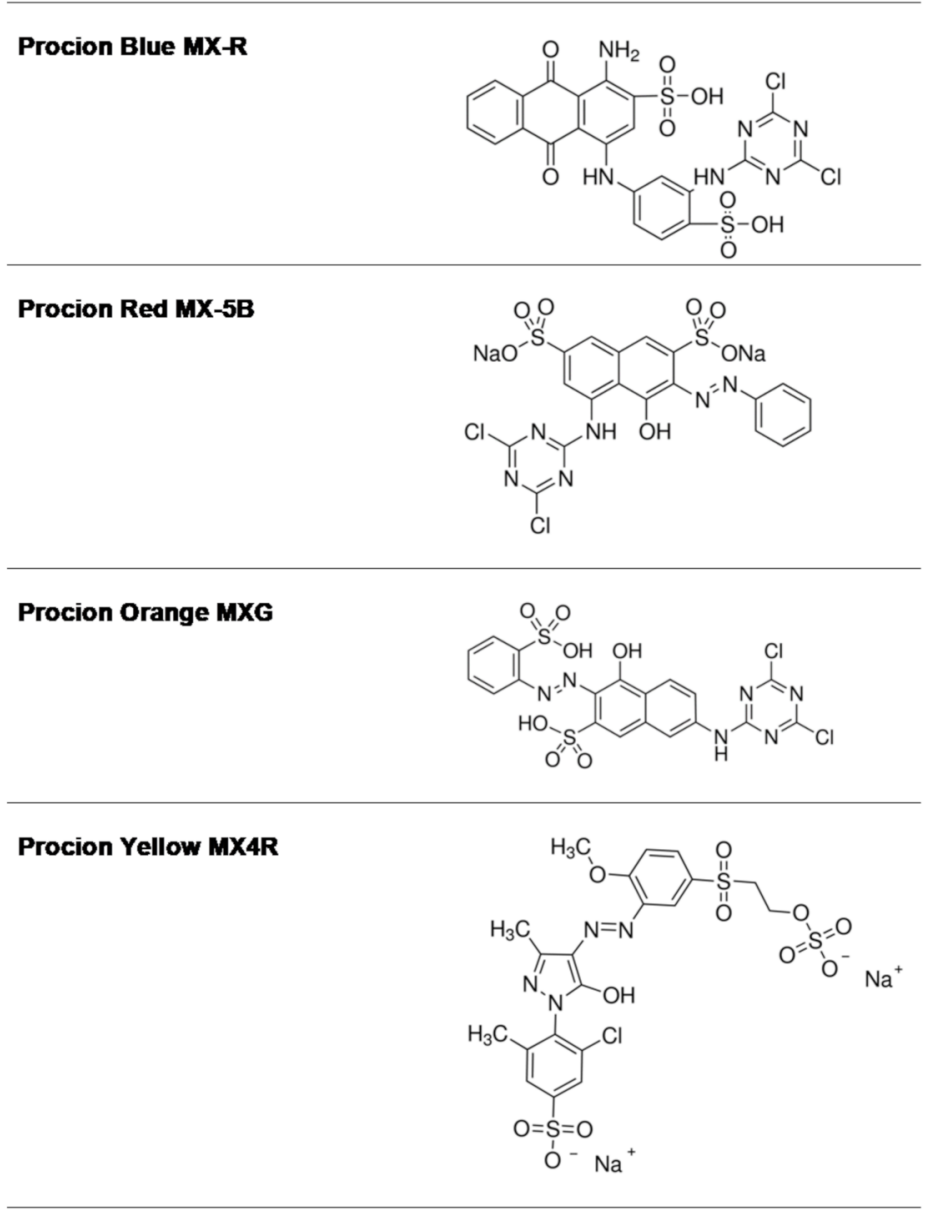

Figure 1. The structure of the anthraquinone and diazo dyes used in the present study.

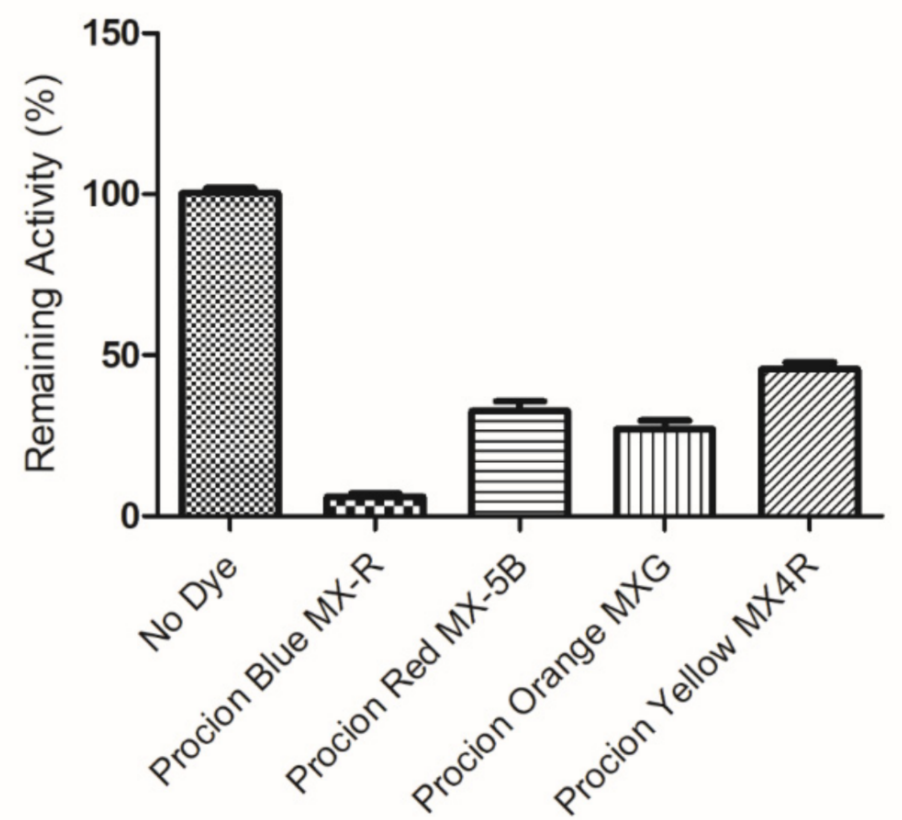

Figure 2. Screening of the inhibition potency of a range of selected diazo and anthraquinone dyes towards hGSTA1-1. 


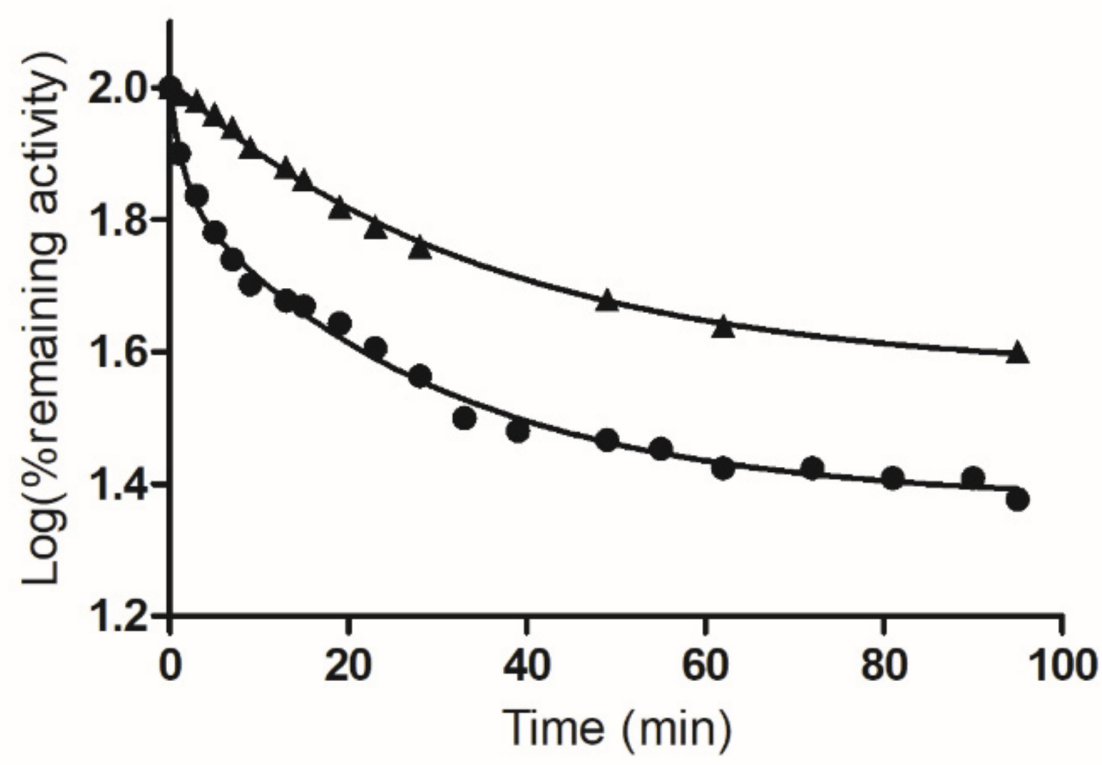

Figure 3. Time course of inactivation of hGSTA1-1 by PBMX-R. The effect of PBMX-R concentration $(5.0 \mu \mathrm{M} \bullet)$ on hGSTA1-1 activity. Time course of inactivation of hGSTA1-1 by 5.0 $\mu \mathrm{M}$ PBMX-R in the presence of S-pNb-GSH (1 mM $\mathbf{\Delta})$. At the times indicated, aliquots were withdrawn and assayed for enzymatic activity. Rate constants for the reaction exhibiting biphasic kinetics were calculated as described previously $[8,31]$ using the computer program GraphPad Prism 5 software (San Diego, CA, USA). The data points show one representative experiment.

A

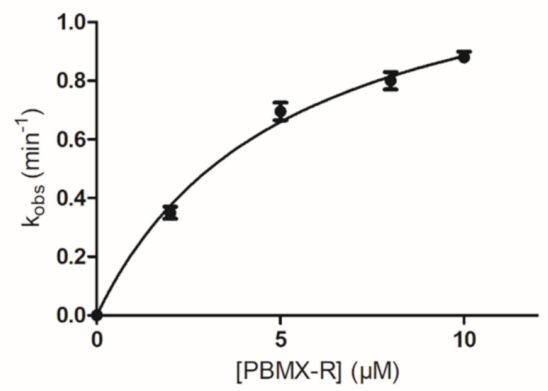

B

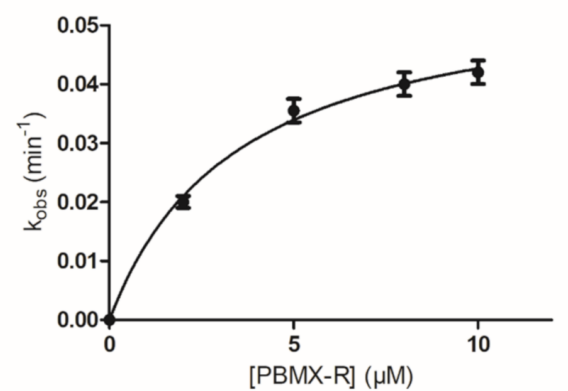

Figure 4. Dependence of the inactivation rate of hGSTA1-1 $\left(k_{o b s}\right)$ on the PBMX-R concentration for the fast $(\mathbf{A})$ and slow $(\mathbf{B})$ phase of inactivation reaction. Kinetic parameters $\left(k_{c a t}\right.$ and $\left.K_{D}\right)$ were calculated as described previously $[8,31]$ using the computer program GraphPad Prism 5 software (San Diego, CA, USA). Data points represent mean values with error.

As shown in Figure 3, the inactivation reaction proceeds in two distinct phases: an initial fast phase of inactivation and a slow phase. Figure 4 shows the dependence of the inactivation rates for the fast and slow phases on the concentration of PBMX-R. Both phases display the characteristics of a chemical reaction since their progression depends on time, and for a certain time, it depends on the concentration of PBMX-R. The observed hyperbolic pattern (Figure 4) consisted of forming a Michaelis-type reversible enzyme:PBMX-R complex, before the formation of the covalent irreversible enzyme-PBMX$\mathrm{R}$ adduct [36]. This indicates that the reaction obeyed pseudo-first-order saturation kinetics. The maximum inactivation rate $\left(k_{3}\right)$ and the dissociation constant $\left(K_{D}\right)$ were determined, and the results are listed in Table 1. 
Table 1. Kinetic parameters of the fast and slow phase of hGSTA1-1 inactivation by PBMX-R.

\begin{tabular}{ccc}
\hline Parameter & Fast & Slow \\
\hline$K_{D}$ & $5.2 \pm 0.5$ & $3.4 \pm 0.2$ \\
$k_{3}$ & $1.3 \pm 0.1$ & $0.06 \pm 0.003$ \\
\hline
\end{tabular}

The selectivity of the interaction between hGSTA1-1 and PBMX-R was demonstrated by the competition observed between the enzyme's inhibitor S-p-nitrobenzyl-glutathione (S-pNb-GSH) and the PBMX-R, as shown in Figure 3. In the presence of S-pNb-GSH $(1 \mathrm{mM})$, the inactivation of the enzyme by PBMX-R is suppressed, suggesting a competition between the two ligands for binding at the same site on the enzyme. The inhibitor S-pNbGSH is an S-substituted glutathione analog, in which the thiol hydrogen of glutathione was replaced by the 4-nitrobenzyl group. S-pNb-GSH binds to hGSTA1-1 and overlaps both the G- and H-site [2].

The stoichiometry of the hGSTA1-1-PBMX-R covalent complex was determined photometrically by measuring the amount of the dye conjugated to the enzyme. The results indicated that the inactivated enzyme contains $1.1 \pm 0.1 \mathrm{~mol}$ of dye per mol of dimeric protein.

\subsection{Kinetic Inhibition Analysis}

Kinetic inhibition analysis was carried out to investigate the type and the inhibition pattern of PBMX-R. Before the analysis, PBMX-R was converted to its monochlotriazine form (hPBMX-R). In hPBMX-R, one chlorine group of the triazine ring was substituted with a hydroxyl group $(-\mathrm{OH})$. This substitution reduces the electrophilicity of the triazine ring [30], and as a consequence, hPBMX-R can function as a reversible inhibitor. We assume that that the small modification in the structure of PBMX-R does not significantly affect its binding mode with the enzyme. The Lineweaver-Burk plots of the dependence of the catalytic reaction on substrate concentration in the presence or absence of different concentrations of hPBMX-R are shown in Figure 5. The inhibition pattern obtained suggests that PBMX-R behaves as a linear competitive inhibitor towards GSH, with $K_{i} 2.02 \pm 0.1 \mu \mathrm{M}$, and mixed-type inhibitor towards CDND, with $K_{i} 14.8 \pm 1.1 \mu \mathrm{M}$.

\subsection{The Identification of hGSTA1-1 Residue Was Modified by PBMX-R}

A molecular docking study was employed to predict the binding site of the PBMX-R. The most favorable mode of binding (FullFitness: - 2090.22, deltaG: -9.97) is illustrated in Figure 6. The PBMX-R binds at a discrete site that is located at the entrance of the substrate-binding site and partially occupies the G-site. This mode of binding consists of the competitive type of inhibition towards GSH and mixed-type inhibition towards CDNB that was obtained by the kinetic inhibition analysis (Figure 5). The anthraquinone ring's sulfonic group occupies the position of glycine carboxylate of GSH at the G-site and forms strong electrostatic interactions with Arg45 and Arg131. The side-chain of Lys127 forms an amino-aromatic interaction with the anthraquinone ring, and Leu123 provides a hydrophobic environment for the binding of anthraquinone. Phe222 seems to be able to form aromatic-aromatic interaction with the benzyl-sulfonate bridging ring of the PBMX-R. The triazine ring is oriented towards the Cys112, suggesting that the side-chain of Cys112 is the nucleophilic group that reacts with the electrophilic carbon on the triazine ring. Other residues, such as Leu108 and Val111, provide van der Waals contacts with the triazine group. 
A

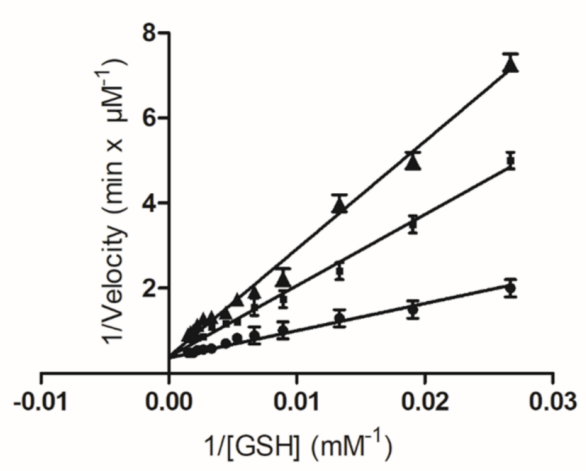

B

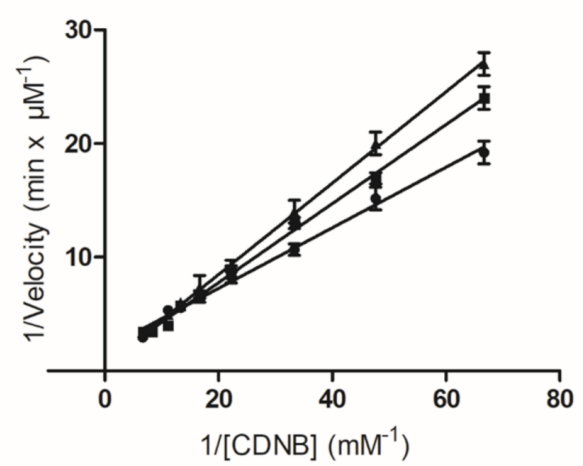

Figure 5. Kinetic inhibition analysis of the interaction of hGSTA1-1 with the hydrolysed PBMX-R (hPBMX-R). Lineweaver-Burk plots of the dependence of the catalytic reaction on substrate concentration in the presence or absence of different concentrations of hPBMX-R. (A) Inhibition of hGSTA1-1 by the hPBMX-R $[(0 \mu \mathrm{M}(\bullet), 2 \mu \mathrm{M}(\mathbf{\square}), 5 \mu \mathrm{M}(\mathbf{\Delta})]$ at a constant CDNB concentration and variable GSH concentrations. (B) Inhibition of hGSTA1-1 by hPBMX-R [(0 $\mu \mathrm{M}(\bullet), 2 \mu \mathrm{M}(\mathbf{\square}), 5 \mu \mathrm{M}(\boldsymbol{\Delta})]$ at a constant GSH concentration and variable CDNB concentrations. The data points represent mean value with error.

A

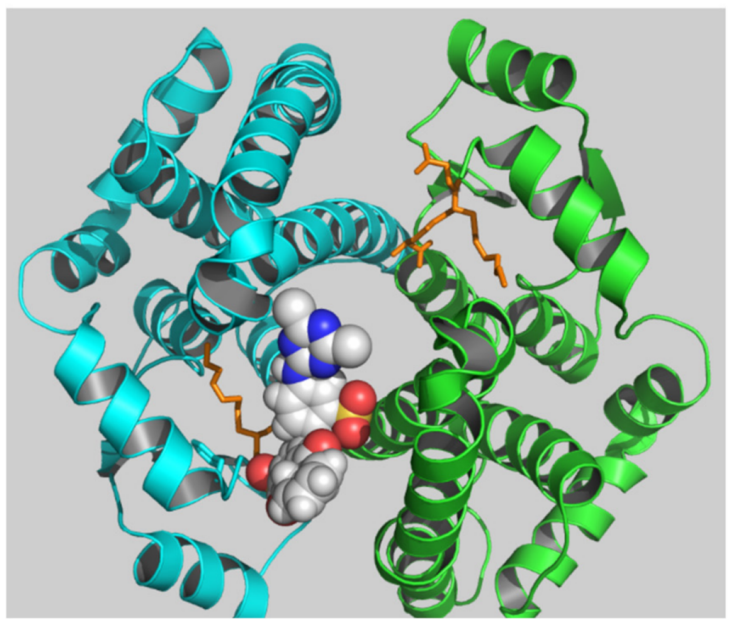

B

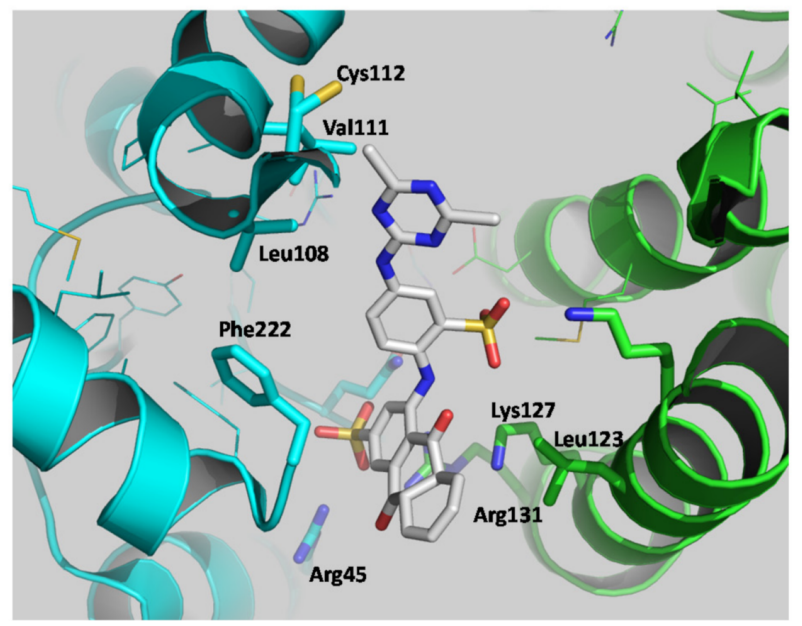

Figure 6. The predicted favorable binding mode of the PBMX-R with the hGSTA1-1 (PDB code 1k31). (A) PBMX-R is shown as a space-filling model, and the inhibitor S-hexyl-glutathione is depicted in stick representation and colored dark yellow. (B) Important side chains that contribute to interaction are shown and labeled. Amino acid side chains and PBMX-R are depicted in stick representation and colored according to the atom type.

Cys112 is a solvent-exposed residue located at the loop (Figure 6) that links the $\mathrm{H} 4$ and $\mathrm{H} 5$ helices. It is involved in forming the large V-shaped cleft formed at the dimer interface, which previous studies showed that it contributes to the formation of L-site [8,36,37]. Previously published data have established that the side-chain of Cys112 is highly reactive and accessible for chemical modification $[8,36,37]$. For example, the reaction of the fluorescence ligand $N$-iodoacetyl- $N^{\prime}$-(5-sulfo-1-naphthyl)ethylenediamine with hGSTA1-1 leads to modification of Cys112 [29,38]. The modification of Cys112 alters the affinity of the anionic dye 8-anilinonaphthalene 1-sulfonate (ANS) with the enzyme, suggesting that this residue participates in the formation of the ligandin binding site [38]. Therefore, it is conceivable to assume that the alkylation of Cys by a bulky compound (such as PBMX-R) blocks the cleft and impedes substrates from binding. 
The modification of Cys112 appears to have a significant impact on the structure of the interface, the volume and the size of the solvent channel, the binding of GSH and substrate, and the product's release. Kumari et al. 2016 have shown that the reaction hGSTA1-1 with phenyl isothiocyanate is achieved at Cys112. The modified enzyme shows more than two orders of magnitude inhibition in vitro [37].

To confirm whether a cysteine residue is involved in the chemical modification reaction, we determined the number of cysteine residues in the PBMX-R-modified and intact enzyme. Cys112 is the only cysteine residue in the sequence of hGSTA1-1 [31]. Total cysteine determination using the DTNB reagent showed that the hGSTA1-1-PBMX-R covalent adduct displayed a loss of $0.97 \pm 0.21 \mathrm{~mol}$ of Cys/mol enzyme dimer, which is close to unity. The loss of cysteine after PBMX-R modification indicates that Cys112 is most probable the nucleophilic target for PBMX-R.

To provide further experimental evidence and establish the involvement of Cys112 in the reaction with PBMX-R, chemical modification with maleimide was carried out. Lyon and Atkins have shown that Cys112 is modified by maleimide and the maleimide-modified enzyme retains most of its activity (92\%) [31]. Incubation of the maleimide-modified enzyme with PBMX-R did not affect the remaining enzyme activity, indicating that the enzyme resistant to further modification by PBMX-R (Figure 7).

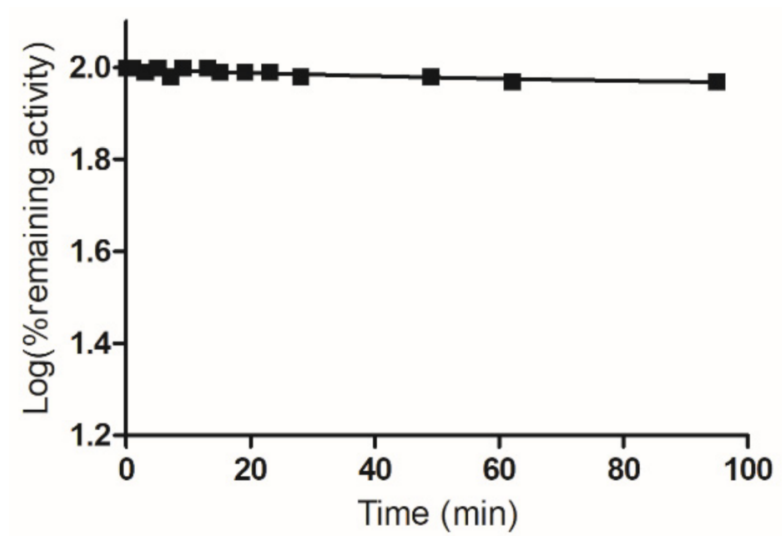

Figure 7. Time course of inactivation of maleimide-modified hGSTA1-1 by PBMX-R. The maleimidemodified hGSTA1-1 was incubated with 5.0 $\mu \mathrm{M}$ PBMX-R (ם). At the times indicated, aliquots were withdrawn and assayed for enzymatic activity. The data points show one representative experiment.

The biphasic kinetics observed (Figure 3) can be explained by assuming that the two subunits are not structurally equivalent. It is conceivable to assume that the reaction of PBMX-R with Cys112 in one subunit alters the susceptibility of Cys112, for chemical modification, in the other subunit, suggesting the existence of inter-subunit communication. This is supported by several pieces of evidence. For example, X-ray crystallography results have shown that the C-terminal region in the apo structure adopts different conformation in the two subunits [27]. Similar negative cooperativity occurs when hGSTA1-1 binds to the dinitrosyl-diglutathionyl iron complex [39].

The observed cooperativity is probable the consequence of the binding of the PBMX-R to the one subunit that alters the structure of the adjacent ligand-free subunit. Analysis of the subunit interface of hGSTA1-1 allows identifying the structural features that seem to contribute to the observed communication. Previous studies have established that the "lock-and-key" motif is a crucial structural element that significantly affects inter-subunit communication (Figure 8) [39,40]. This motif is formed by Phe52 and Met51 from one subunit that interacts with a hydrophobic patch on the other subunit, composed in part by Met94, Phe136, and Val139. A network of interactions allows a conformational change to be transmitted via the $\alpha$-helix $\mathrm{H} 4$ to Cys112. As a result, this conformational change may restrict the accessibility of Cys112 at the second subunit for reaction with PBMX-R. 


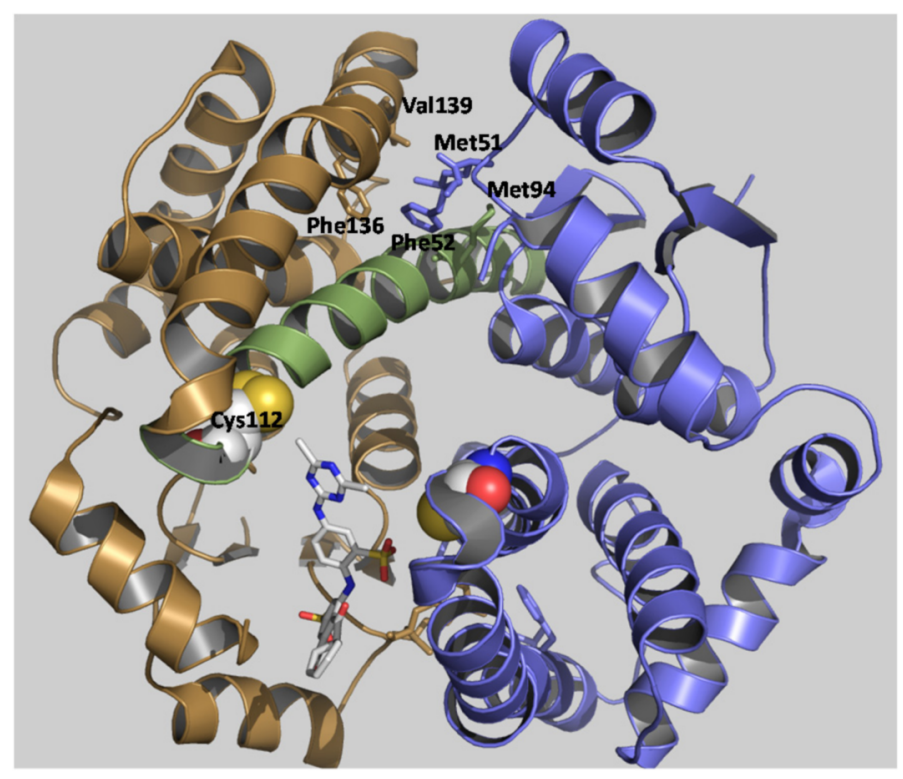

Figure 8. Predicted structural communication between hGSTA1-1 subunits (PDB code 1k31). Amino acid residues that form the lock-and-key motif (Phe52, Met51, Phe136 and Val139) are shown in a stick representation and labeled. PBMX-R is shown in a stick representation and colored according to the atom type. $\alpha$-Helix- 4 is colored green. Cys112 is shown in sphere representation and colored according to the atom type.

\section{Materials and Methods}

\subsection{Materials}

All reagents and chemicals were of analytical grade and obtained from Sigma-Aldrich Co (St. Louis, MO, USA).

\subsection{Heterologous Expression and Purification of Recombinant Human Glutathione Transferase A1-1}

The isoenzyme hGSTA1-1 was expressed in E. coli B121 (DE3) cells and purified by affinity chromatography on immobilized GSH as described previously [41]. Protein concentration was determined by the method of Bradford, using BSA as standard [42].

\subsection{Assay of GST Activity and Inhibition Analysis by Triazine Dyes}

Assay of GST activity was carried out using the CDNB/GSH system as described previously [41]. The inhibition of hGSTA1-1 by DCTDs was evaluated by measuring the ability of the compounds to bind and inhibit enzyme activity. The inhibition potency was measured with the CDNB/GSH assay system in the presence of $20 \mu \mathrm{M}$ dye.

$$
\% I=100 \frac{R_{\mathrm{o}}-R_{\mathrm{i}}}{R_{\mathrm{o}}}
$$

where $R_{O}$ is the rate of absorbance increase for the uninhibited reaction and $R_{i}$ is the rate of increase for the inhibited reaction. Both $R_{i}$ and $R_{o}$ correspond to the same substrate concentration.

Kinetic inhibition analysis was carried out as described previously [43]. Before kinetic analysis, the dichlorotriazine dye PBMX-R was converted to its monochlorotriazine form by hydrolysis $[30,31]$. The kinetic data were analyzed by nonlinear regression analysis using the computer program GraphPad Prism 5 software (San Diego, CA, USA).

\subsection{Enzyme Inactivation Studies by PBMX-R}

Inactivation of hGSTA1-1 was performed in $1 \mathrm{~mL}$ of incubation mixture containing: potassium phosphate buffer pH 7 (20 mM), PBMX-R, (0-10.0 $\mu \mathrm{M})$; enzyme, (0.1 units). The 
inactivation rate was followed by periodically removing samples (5-20 $\mu \mathrm{L})$ for assay of enzymatic activity. The chemical reaction between an enzyme and an irreversible inhibitor, such as PBMX-R, can be described as follows:

$$
\mathrm{E}+\mathrm{PBMX}-\mathrm{R} \stackrel{K_{D}}{\rightleftarrows} \mathrm{E}: \mathrm{PBMX}-\mathrm{R} \stackrel{k_{3}}{\rightarrow} \mathrm{E}-\mathrm{PBMX}-\mathrm{R}+\mathrm{L}
$$

where E and PBMX-R are the free enzyme and the irreversible inhibitor, respectively, E:PBMX-R is the intermediate, Michaelis-type enzyme:inhibitor reversible complex, EPBMX-R is the covalently modified enzyme by the inhibitor, $K_{D}$ is the dissociation constant of the complex E:PBMX-R, $k_{3}$ is the maximum rate of inactivation and $\mathrm{L}$ is the reaction's leaving group. By assuming Briggs and Haldane conditions and excess of inhibitor over enzyme concentration $([\mathrm{I}]>>[\mathrm{E}])$, the kinetic equation describing the interaction is given by the following formula $[30,31,44,45]$ :

$$
k_{o b s}=\frac{k_{3}[I]}{K_{D}+[I]}
$$

where $k_{o b s}$ is the observed rate of inactivation of the enzyme by the non-reversible inhibitor, and $[\mathrm{I}]$ is the concentration of the non-reversible inhibitor. The observed rate of enzyme inactivation $\left(k_{o b s}\right)$ for each concentration of PBMX-R was determined from the curves of the $\log \left(\%\right.$ remaining enzymatic activity) versus time $t(\mathrm{~min})$ at $25^{\circ} \mathrm{C}$. Rate constants for the reaction exhibiting biphasic kinetics were calculated as described previously $[8,31,44-46]$ using the computer program GraphPad Prism 5 software (San Diego, CA, USA).

Inactivation studies of hGSTA1-1 by PBMX-R in the presence of S-pNb-GSH were performed in $1 \mathrm{~mL}$ of incubation mixture containing: potassium phosphate buffer $\mathrm{pH} 7$ (20 $\mu \mathrm{mol})$; PBMX-R, (5 $\mu \mathrm{M})$; S-pNb-GSH (1 mM); enzyme (0.1 units).

The stoichiometry of PBMX-R/hGSTA1-1 conjugate was measured photometrically at $620 \mathrm{~nm}$ as described earlier [30].

\subsection{Modification of hGSTA1-1 with DTNB and N-ethylmaleimide}

Determination of enzyme cysteine-SH groups with 5,5-dithio-bis-(2-nitrobenzoic acid) was achieved using Ellman's method [47] as described by Karpusas et al., 2013 [8]. Modification of hGSTA1-1 by N-ethylmaleimide (1 $\mathrm{mM})$ was carried out according to Lyon and Atkins (2002) [36].

\subsection{The Interaction of PBMX-R with hGSTA1-1 by Molecular Docking}

The putative binding sites of PBMX-R were identified by molecular-docking using the SwissDock program and EADock DSS software [48,49]. The crystal structure of hGSTA11 with PDB code $1 \mathrm{k} 31$ (1.5 ̊ resolution) was used for docking [50]. The docking was performed with no region of interest defined (blind docking). CHARMM energies were measured, and binding modes are evaluated using FACTS and clustered [51]. For inspection of models and crystal structures, the program PyMOL (http:/ / www.pymol.org/ (accessed on 17 April 2021)) was used.

\section{Conclusions}

The present study showed that the dichlorotriazine dye PBMX-R is an irreversible alkylating inhibitor for hGSTA1-1. Considering that hGSTA1-1 contributes significantly to developing multidrug resistance to many anticancer drugs, the results suggest that PBMX-R is a useful probe suitable for assessing by kinetic means the drugability of the enzyme in future drug-design efforts. The outcome of the study can facilitate a more rational development of effective GST-targeted cancer chemosensitizers.

Author Contributions: Conceptualization, M.H.A.; M.M.M. and N.E.L.; methodology, formal analysis and investigation, M.H.A.; M.M.M.; A.I.F.; N.E.L.; writing—original draft preparation, M.H.A.; M.M.M.; N.E.L. All authors have read and agreed to the published version of the manuscript. 
Funding: This project was supported by the Deanship of Scientific Research at Prince Sattam bin Abdulaziz University under the research project 2020/03/16815.

Institutional Review Board Statement: Not applicable.

Informed Consent Statement: Not applicable.

Data Availability Statement: Data is contained within the article.

Conflicts of Interest: The authors declare no conflict of interest.

Sample Availability: More computational data are available upon request.

\begin{tabular}{ll}
\multicolumn{2}{l}{ Abbreviations } \\
CB3GA & Cibacron blue 3GA \\
CDNB & 1-chloro-2,4-dinitrobenzene \\
DCTD & dichlorotriazine dye \\
GSH & glutathione \\
GST & glutathione transferase \\
G-site & glutathione-binding site \\
hGSTA1-1 & human glutathione transferase A1-1 \\
hPBMX-R & hydrolyzed PBMX-R \\
H-ste & hydrophobic binding site for electrophilic substrates \\
PBMX-R & Procion blue MX-R \\
L-site & ligandin-binding site; (L-site) \\
S-pNb-GSH & S-p-nitrobenzyl-glutathione
\end{tabular}

\section{References}

1. Allocati, N.; Masulli, M.; Di Ilio, C.; Federici, L. Glutathione transferases: Substrates, inihibitors and pro-drugs in cancer and neurodegenerative diseases. Oncogenesis 2018, 7, 8. [CrossRef] [PubMed]

2. Sinning, I.; Kleywegt, G.J.; Cowan, S.W.; Reinemer, P.; Dirr, H.W.; Huber, R.; Gilliland, G.L.; Armstrong, R.N.; Ji, X.; Board, P.G.; et al. Structure determination and refinement of human alpha class glutathione transferase A1-1, and a comparison with the Mu and Pi class enzymes. J. Mol. Biol. 1993, 232, 192-212. [CrossRef] [PubMed]

3. Mannervik, B. The isoenzymes of glutathione transferase. Advan. Enzymol. Rel. Areas Mol. Biol. 1985, 57, $357-417$.

4. Mannervik, B. Five decades with glutathione and the GSTome. J. Biol. Chem. 2012, 287, 6072-6083. [CrossRef]

5. Perperopoulou, F.; Pouliou, F.; Labrou, N.E. Recent advances in protein engineering and biotechnological applications of glutathione transferases. Crit. Rev. Biotechnol. 2018, 38, 511-528. [CrossRef]

6. Mohana, K.; Achary, A. Human cytosolic glutathione-S-transferases: Quantitative analysis of expression, comparative analysis of structures and inhibition strategies of isozymes involved in drug resistance. Drug Metab. Rev. 2017, 49, 318-337. [CrossRef]

7. Pljesa-Ercegovac, M.; Savic-Radojevic, A.; Matic, M.; Coric, V.; Djukic, T.; Radic, T.; Simic, T. Glutathione Transferases: Potential Targets to Overcome Chemoresistance in Solid Tumors. Int. J. Mol. Sci. 2018, 19, 3785. [CrossRef]

8. Karpusas, M.; Axarli, I.; Chiniadis, L.; Papakyriakou, A.; Bethanis, K.; Scopelitou, K.; Clonis, Y.D.; Labrou, N.E. The interaction of the chemotherapeutic drug chlorambucil with human glutathione transferase A1-1: Kinetic and structural analysis. PLoS ONE 2013, 8, e56337. [CrossRef]

9. Smitherman, P.K.; Townsend, A.J.; Kute, T.E.; Morrow, C.S. Role of multidrug resistance protein 2 (MRP2, ABCC2) in alkylating agent detoxification: MRP2 potentiates glutathione S-transferase A1-1-mediated resistance to chlorambucil cytotoxicity. J. Pharmacol. Exp. Ther. 2004, 308, 260-267. [CrossRef]

10. Sharma, R.; Ellis, B.; Sharma, A. Role of alpha class glutathione transferases (GSTs) in chemoprevention: GSTA1 and A4 overexpressing human leukemia (HL60) cells resist sulforaphane and curcumin induced toxicity. Phytother. Res. 2011, 25, 563-568. [CrossRef]

11. Ricci, G.; De Maria, F.; Antonini, G.; Turella, P.; Bullo, A.; Stella, L.; Filomeni, G.; Federici, G.; Caccuri, A.M. 7-Nitro-2,1,3benzoxadiazole derivatives, a new class of suicide inhibitors for glutathione S-transferases. Mechanism of action of potential anticancer drugs. J. Biol. Chem. 2005, 280, 26397-26405. [CrossRef]

12. Zou, M.; Hu, X.; Xu, B.; Tong, T.; Jing, Y.; Xi, L.; Zhou, W.; Lu, J.; Wang, X.; Yang, X.; et al. Glutathione S transferase isozyme alpha 1 is predominantly involved in the cisplatin resistance of common types of solid cancer. Oncol. Rep. 2019, 41, 989-998. [CrossRef]

13. Kumar, M.; Martin, A.; Nirgude, S.; Chaudhary, B.; Mondal, S.; Sarkar, A. Quinacrine inhibits GSTA1 activity and induces apoptosis through G1/S arrest and generation of ROS in human non-small cell lung cancer cell lines. Oncotarget 2020, 11, 1603-1617; Erratum in: Oncotarget 2020, 11, 4364-4365. [CrossRef]

14. Guo, W.; Tan, H.Y.; Chen, F.; Wang, N.; Feng, Y. Targeting Cancer Metabolism to Resensitize Chemotherapy: Potential Development of Cancer Chemosensitizers from Traditional Chinese Medicines. Cancers 2020, 12, 404. [CrossRef] 
15. De Luca, A.; Parker, L.J.; Ang, W.H.; Rodolfo, C.; Gabbarini, V.; Hancock, N.C.; Palone, F.; Mazzetti, A.P.; Menin, L.; Morton, C.J.; et al. A structure-based mechanism of cisplatin resistance mediated by glutathione transferase P1-1. Proc. Natl. Acad. Sci. USA 2019, 116, 13943-13951. [CrossRef] [PubMed]

16. Dong, S.C.; Sha, H.H.; Xu, X.Y.; Hu, T.M.; Lou, R.; Li, H.; Wu, J.Z.; Dan, C.; Feng, J. Glutathione S-transferase $\pi$ : A potential role in antitumor therapy. Drug Des. Dev. Ther. 2018, 12, 3535-3547. [CrossRef]

17. Chatterjee, A.; Gupta, S. The multifaceted role of glutathione S-transferases in cancer. Cancer Lett. 2018, 433, 33-42. [CrossRef]

18. Ansari, M.I.; Khan, M.M.; Saquib, M.; Khatoon, S.; Hussain, M.K. Dithiolethiones: A privileged pharmacophore for anticancer therapy and chemoprevention. Future Med. Chem. 2018, 10, 1241-1260. [CrossRef]

19. Sharma, A.; Patrick, B.; Li, J.; Sharma, R.; Jeyabal, P.V.; Reddy, P.M.; Awasthi, S.; Awasthi, Y.C. Glutathione S-transferases as antioxidant enzymes: Small cell lung cancer (H69) cells transfected with hGSTA1 resist doxorubicin-induced apoptosis. Arch. Biochem. Biophys. 2006, 452, 165-173. [CrossRef]

20. Pathania, S.; Bhatia, R.; Baldi, A.; Singh, R.; Rawal, R.K. Drug metabolizing enzymes and their inhibitors' role in cancer resistance. Biomed. Pharmacother. 2018, 105, 53-65. [CrossRef]

21. Xie, Y.; Dahlin, J.L.; Oakley, A.J.; Casarotto, M.G.; Board, P.G.; Baell, J.B. Reviewing Hit Discovery Literature for Difficult Targets: Glutathione Transferase Omega-1 as an Example. J. Med. Chem. 2018, 61, 7448-7470. [CrossRef] [PubMed]

22. Zhang, X.Y.; Elfarra, A.A. Toxicity mechanism-based prodrugs: Glutathione-dependent bioactivation as a strategy for anticancer prodrug design. Expert Opin. Drug Discov. 2018, 13, 815-824. [CrossRef] [PubMed]

23. Pouliou, F.M.; Thireou, T.N.; Eliopoulos, E.E.; Tsoungas, P.G.; Labrou, N.E.; Clonis, Y.D. Isoenzyme- and allozyme-specific inhibitors: 2,2'-dihydroxybenzophenones and their carbonyl $\mathrm{N}$-analogues that discriminate between human glutathione transferase A1-1 and P1-1 allozymes. Chem. Biol. Drug Des. 2015, 86, 1055-1063. [CrossRef] [PubMed]

24. Premetis, G.; Marugas, P.; Fanos, G.; Vlachakis, D.; Chronopoulou, E.G.; Perperopoulou, F.; Dubey, K.K.; Shukla, P.; Foudah, A.I.; Muharram, M.M.; et al. The Interaction of the Microtubule Targeting Anticancer Drug Colchicine with Human Glutathione Transferases. Curr. Pharm. Des. 2020, 26, 5205-5212. [CrossRef]

25. Dirr, H.W.; Wallace, L.A. Role of the C-terminal helix 9 in the stability and ligandin function of class alpha glutathione transferase A1-1. Biochemistry 1999, 38, 15631-15640. [CrossRef]

26. Grahn, E.; Novotny, M.; Jakobsson, E.; Gustafsson, A.; Grehn, L.; Olin, B.; Madsen, D.; Wahlberg, M.; Mannervik, B.; Kleywegt, G.J. New crystal structures of human glutathione transferase A1-1 shed light on glutathione binding and the conformation of the C-terminal helix. Acta Cryst. 2006, D62, 197-207. [CrossRef]

27. Misquitta, S.A.; Colman, R.F. Communication between the two active sites of glutathione S-transferase A1-1, probed using wild-type-mutant heterodimers. Biochemistry 2005, 44, 8608-8619. [CrossRef]

28. Sayed, Y.; Hornby, J.A.; Lopez, M.; Dirr, H. Thermodynamics of the ligandin function of human class Alpha glutathione transferase A1-1: Energetics of organic anion ligand binding. Biochem. J. 2002, 363, 341-346. [CrossRef]

29. Sayed, Y.; Wallance, L.A.; Dirr, H.W. The hydrophobic lock-and-key intersubunit motif of glutathione transferase A1-1: Implications for catalysis, ligandin function and stability. FEBS Lett. 2000, 465, 169-172. [CrossRef]

30. Labrou, N.E.; Clonis, Y.D. The interaction of Candida boidinii formate dehydrogenase with a new family of chimeric biomimetic dye-ligands. Arch. Biochem. Biophys. 1995, 316, 169-178. [CrossRef]

31. Platis, M.; Vlachakis, D.; Foudah, A.I.; Muharram, M.M.; Alqarni, M.H.; Papageorgiou, A.C.; Labrou, N.E. The interaction of Schistosoma japonicum glutathione transferase with Cibacron blue 3GA and its fragments. Med. Chem. 2021, in press. [CrossRef]

32. Axarli, I.A.; Rigden, D.J.; Labrou, N.E. Characterization of the ligandin site of maize glutathione S-transferase I. Biochem. J. 2004, 382, 885-893. [CrossRef]

33. Platis, D.; Smith, B.J.; Huyton, T.; Labrou, N.E. Structure-guided design of a novel class of benzyl-sulfonate inhibitors for influenza virus neuraminidase. Biochem. J. 2006, 399, 215-223. [CrossRef]

34. Oakley, A.J.; Lo Bello, M.; Nuccetelli, M.; Mazzetti, A.P.; Parker, M.W. The ligandin (non-substrate) binding site of human Pi class glutathione transferase is located in the electrophile binding site (H-site). J. Mol. Biol. 1999, 291, 913-926. [CrossRef]

35. Mosialou, E.; Morgenstern, R. Inhibition studies on rat liver microsomal glutathione transferase. Chem. Biol. Interact. 1990, 74, 275-280. [CrossRef]

36. Lyon, R.P.; Atkins, W.M. Kinetic characterization of native and cysteine 112-modified glutathione S-transferase A1-1: Reassessment of nonsubstrate ligand binding. Biochemistry 2002, 41, 10920-10927. [CrossRef]

37. Kumari, V.; Dyba, M.A.; Holland, R.J.; Liang, Y.H.; Singh, S.V.; Ji, X. Irreversible Inhibition of Glutathione S-Transferase by Phenethyl Isothiocyanate (PEITC), a Dietary Cancer Chemopreventive Phytochemical. PLoS ONE 2016, 11, e0163821. [CrossRef]

38. Sluis-Cremer, N.; Wallace, L.; Burke, J.; Stevens, J.; Dirr, H. Aflatoxin B1 and sulphobromophthalein binding to the dimeric human glutathione S-transferase A1-1: A fluorescence spectroscopic analysis. Eur. J. Biochem. 1998, 257, 434-442. [CrossRef]

39. Bocedi, A.; Fabrini, R.; Farrotti, A.; Stella, L.; Ketterman, A.J.; Pedersen, J.Z.; Allocati, N.; Lau, P.C.; Grosse, S.; Eltis, L.D.; et al. The impact of nitric oxide toxicity on the evolution of the glutathione transferase superfamily: A proposal for an evolutionary driving force. J. Biol. Chem. 2013, 288, 24936-24947. [CrossRef]

40. Bocedi, A.; Fabrini, R.; Lo Bello, M.; Caccuri, A.M.; Federici, G.; Mannervik, B.; Cornish-Bowden, A.; Ricci, G. Evolution of Negative Cooperativity in Glutathione Transferase Enabled Preservation of Enzyme Function. J. Biol. Chem. 2016, 291, 26739-26749. [CrossRef] 
41. Axarli, I.; Muleta, A.W.; Chronopoulou, E.G.; Papageorgiou, A.C.; Labrou, N.E. Directed evolution of glutathione transferases towards a selective glutathione-binding site and improved oxidative stability. Biochim. Biophys. Acta Gen. Subj. 2017, 1861, 3416-3428. [CrossRef] [PubMed]

42. Bradford, M.M. A rapid and sensitive method for the quantitation of microgram quantities of protein utilizing the principle of protein-dye binding. Anal. Biochem. 1976, 72, 248-254. [CrossRef]

43. Axarli, I.; Labrou, N.E.; Petrou, C.; Rassias, N.; Cordopatis, P.; Clonis, Y.D. Sulphonamide-based bombesin prodrug analogues for glutathione transferase, useful in targeted cancer chemotherapy. Eur. J. Med. Chem. 2009, 44, 2009-2016. [CrossRef] [PubMed]

44. King, M.M.; Colman, R. Affinity labeling of nicotinamide adenine dinucleotide dependent isocitrate dehydrogenase by the $2^{\prime}, 3^{\prime}$-dialdehyde derivative of adenosine $5^{\prime}$-diphosphate. Evidence for the formation of an unusual reaction product. Biochemistry 1983, 22, 1656-1665. [CrossRef] [PubMed]

45. Kitz, R.; Wilson, I.B. Esters of methanesulfonic acid as irreversible inhibitors of acetylcholinesterase. J. Biol. Chem. 1962, 237, 3245-3249. [CrossRef]

46. Rendina, A.R.; Cheng, D. Characterization of the inactivation of rat fatty acid synthase by C75: Inhibition of partial reactions and protection by substrates. Biochem. J. 2005, 388, 895-903. [CrossRef] [PubMed]

47. Eyer, P.; Worek, F.; Kiderlen, D.; Sinko, G.; Stuglin, A.; Simeon-Rudolf, V.; Reiner, E. Molar absorption coefficients for the reduced Ellman reagent: Reassessment. Anal. Biochem. 2003, 312, 224-227. [CrossRef]

48. Grosdidier, A.; Zoete, V.; Michielin, O. SwissDock, a protein-small molecule docking web service based on EADock DSS. Nucleic Acids Res. 2001, 39, W270-W277. [CrossRef]

49. Perperopoulou, F.; Ataya, F.S.; Fouad, D.; Malik, A.; Saeed, H.M.; Labrou, N.E. Biochemical Characterization of the Detoxifying Enzyme Glutathione Transferase P1-1 from the Camel Camelus Dromedarius. Cell Biochem. Biophys. 2016, 74, 459-472. [CrossRef]

50. Le Trong, I.; Stenkamp, R.E.; Ibarra, C.; Atkins, W.M.; Adman, E.T. 1.3-A resolution structure of human glutathione S-transferase with S-hexyl glutathione bound reveals possible extended ligandin binding site. Proteins 2002, 48, 618-627. [CrossRef]

51. Grosdidier, A.; Zoete, V.; Michielin, O. EADock: Docking of small molecules into protein active sites with a multiobjective evolutionary optimization. Proteins 2007, 67, 1010-1025. [CrossRef] 